Article

\title{
Rapid Bioassay-Guided Isolation of Antibacterial Clerodane Type Diterpenoid from Dodonaea viscosa (L.) Jaeq.
}

Muhammad Khurram 1,2,3,†,*, Linda A. Lawton ${ }^{2, \dagger}$, Christine Edwards ${ }^{2, \dagger}$, Marcello Iriti ${ }^{4, *}$, Abdul Hameed ${ }^{3,5}$, Murad A. Khan ${ }^{6}$, Farman A. Khan ${ }^{7}$ and Shafiq ur Rahman ${ }^{1}$

1 Department of Pharmacy, Shaheed Benazir Bhutto University, Sheringal, Dir Upper 18000, Pakistan; E-Mail: shafiq@sbbu.edu.pk

2 School of Pharmacy and Life Sciences, the Robert Gordon University, Aberdeen AB25 1HG, UK; E-Mails: 1.lawton@rgu.ac.uk (L.A.L.); c.edwards@rgu.ac.uk (C.E.)

3 Department of Microbiology, Quaid-i-Azam University, Islamabad 45320, Pakistan; E-Mail: ahameed@qau.edu.pk

4 Department of Agricultural and Environmental Sciences, Milan State University, Milan 20133, Italy

5 Centre for Interdisciplinary Research in Basic Sciences, International Islamic University, Islamabad 44000, Pakistan; E-Mail: abdul.hameed@iiu.edu.pk

6 Department of Chemistry, Kohat University of Science \& Technology, Kohat 26000, Pakistan; E-Mail: dr.murad@kust.edu.pk

7 Department of Chemistry, Shaheed Benazir Bhutto University, Sheringal, Dir Upper 18000, Pakistan; E-Mail: farmanali@sbbu.edu.pk

$\dagger$ These authors contributed equally to this work.

* Authors to whom correspondence should be addressed; E-Mails: pharmacistkhurram@gmail.com or drmkhurram@sbbu.edu.pk (M.K.); marcello.iriti@unimi.it (M.I.);

Tel.: +92-944-885-400 (M.K.); +39-02-5031-6766 (M.I.); Fax: +92-944-885-805 (M.K.); +39-02-5031-6781 (M.I.).

Academic Editor: Chang Won Choi

Received: 6 March 2015 / Accepted: 17 August 2015 / Published: 27 August 2015

Abstract: Plant extracts are complex matrices and, although crude extracts are widely in use,
purified compounds are pivotal in drug discovery. This study describes the application of
automated preparative-HPLC combined with a rapid off-line bacterial bioassay, using
reduction of a tetrazolium salt as an indicator of bacterial metabolism. This approach
enabled the identification of fractions from Dodonaea viscosa that were active against
Staphylococcus aureus and Escherichia coli, which, ultimately, resulted in the identification 
of a clerodane type diterpenoid, $6 \beta$-hydroxy-15,16-epoxy-5 $\beta, 8 \beta, 9 \beta, 10 \alpha$-cleroda-3, 13(16), 14-trien-18-oic acid, showing bacteriostatic activity (minimum inhibitory concentration $(\mathrm{MIC})=64-128 \mu \mathrm{g} / \mathrm{mL}$ ) against test bacteria. To the best of our knowledge, this is the first report on antibacterial activity of this metabolite from $D$. viscosa.

Keywords: Dodonaea viscosa; preparative HPLC; XTT assay; clerodane diterpenoid

\section{Introduction}

The global presence and rise of antibiotic resistant pathogens and decline in antibiotic drug discovery programs by pharmaceutical companies are prompting the scientific community to search for new and also re-examine old sources of bioactive chemicals in order to identify potential drugs [1]. Medicinal plants are an area under focus since their secondary metabolites encompass a significant number of drugs used in current therapeutics and there is no doubt in their potential as the source of new medicines [2].

Dodonaea viscosa (L.) Jaeq. is an evergreen shrub in Pakistan and is locally known as Ghawraskay (Pushto). It is traditionally used to treat a wide range of medical conditions from colds to malaria $[3,4]$, and crude extracts have been shown to be active against bacterial, viral, fungal and protozoal pathogens [5-7]. However, despite numerous phytochemical investigations, only a single compound, hautriwaic acid, with moderate antibacterial activity has been characterized [8].

Isolation and characterization of bioactive molecules from crude plant extracts or fractioned extracts are challenging tasks. This is mainly due to the presence of a large number of metabolites with close physicochemical properties with often complementing bioactivities. However, in order to standardize them, their separation is necessary. Chromatographic methods have revolutionized the separation of such complex mixtures and the combination of chromatography with spectroscopic and spectrophotometric methods such as mass spectroscopy, UV, NMR etc. has further eased the task. In this context, preparative HPLC has shown to be an essential tool for producing high quality natural products and if strict quality control is undertaken, the approach ensures reliable screening results $[9,10]$.

Currently, cell viability assays make use of one of several tetrazolium salts in a microplate format. Metabolically active cells reduce the tetrazolium salts and result in coloured formazan products that can be simply read by a plate reader, thus offering rapid records on the metabolic status of the cell [11]. XTT (2,3-bis(2-methoxy-4-nitro-5-sulfophenyl)-2H-tetrazolium-5-carboxanilide) is a tetrazolium salt that does not require the additional solubilisation step as required in the 3-(4,5-dimethylthiazol-2-yl)2,5-diphenyltetrazolium bromide (MTT) assay and yields a reduced formazan product that is water soluble [11]. The XTT assay is exploited in determination of antimicrobial activity of simple plant extracts $[12,13]$. This study describes the combination of automated preparative HPLC in combination with an XTT bioassay for rapid identification of antibacterial fractions and derived active compound from $D$. viscosa. 


\section{Results and Discussion}

\subsection{Fractionation of Plant Material}

Liquid-liquid fractionation of the crude aqueous extract of D. viscosa resulted in $75 \mathrm{~g}$ of an $n$-hexane fraction (H), $70 \mathrm{~g}$ of a dichloromethane fraction (D), $92 \mathrm{~g}$ of an ethyl acetate fraction (E), $81 \mathrm{~g}$ of an $n$-butanol fraction (B) that spontaneously solidified, and $126 \mathrm{~g}$ of thick suspension of an aqueous fraction (A).

\subsection{Preliminary Antibacterial Screening}

Extracts of $D$. viscosa derived from hexane and ethyl acetate were active against $E$. coli (the National Collection of Industrial, Marine and Food Bacteria (NCIMB) 8797) and S. aureus (NCIMB 6571), whereas the butanol extract was only active against $S$. aureus (Table 1). Previous studies on D. viscosa fractions showed bacteriostatic activity against Gram positive bacteria, but not Gram negative such as E. coli $[5,6]$; our results indicated that the hexane and ethyl acetate fractions inhibited E. coli. These opposite findings may be due to differences in the plant material, extraction protocols and test strains used. As there is growing interest in the generation of libraries of simplified extracts prior to screening $[9,10]$, our approach aimed to select those extracts which exhibited antibacterial activity and use preparative HPLC with the XTT assay for rapid screening of a large number of fractions.

Table 1. Antibacterial activity (average zones of inhibitions in $\mathrm{mm} \pm \mathrm{SD}$ ) of crude solvent fractions determined by disk diffusion assay.

\begin{tabular}{ccc}
\hline D. viscosa & \multicolumn{2}{c}{ Test Bacteria } \\
\hline Fraction & E. coli (NCIMB 8797) & S. aureus (NCIMB 6571) \\
Hexane (H) & $12.5 \pm 0.5$ & $11.4 \pm 0.5$ \\
Dichloromethane (D) & 0.0 & 0.0 \\
Ethyl acetate (E) & $9.7 \pm 0.3$ & $9.0 \pm 0.2$ \\
Butanol (B) & 0.0 & $10.0 \pm 0.2$ \\
Aqueous (A) & 0.0 & 0.0 \\
Ciprofloxacin & $31.0 \pm 0.5$ & - \\
Clarithromycin & - & $28.6 \pm 0.5$ \\
\hline
\end{tabular}

Ciprofloxacin (10 $\mu \mathrm{g} /$ disk); Clarithromycin (15 $\mu \mathrm{g} / \mathrm{disk})$ (positive controls); Methanol (negative control).

\subsection{Optimization of XTT (2,3-Bis(2-methoxy-4-nitro-5-sulfophenyl)-2H-tetrazolium-5- carboxanilide) Bioassay}

Ciprofloxacin $(50 \mu \mathrm{g} / \mathrm{mL})$ and clarithromycin $(25 \mu \mathrm{g} / \mathrm{mL})$ inhibited the test strains of $E$. coli and $S$. aureus, respectively, after $24 \mathrm{~h}$ incubation in the XTT assay, as shown by the decreased absorbance. The effect of ciprofloxacin on $E$. coli was evident after $2 \mathrm{~h}$ incubation, with absorbance in the treated cells at 0.042 compared to the solvent control at 0.098 . However, $24 \mathrm{~h}$ incubation was necessary to obtain an evident result on the effect of clarithromycin on $S$. aureus; therefore $24 \mathrm{~h}$ incubation was selected as incubation period. 


\subsection{Generic Preparative HPLC-XTT Bioassay}

The use of solvents such as methanol and water along with a volume-based fractionation strategy was necessary as the active component(s) may not contain a chromophore. For the extract, a total of 52 primary fractions were collected and each fraction was evaluated against the two test bacteria using the XTT assay. No bioactivity was detected in the fractions from the ethyl acetate extract of D. viscosa, despite the activity against both bacteria reported in disk diffusion assay (Table 1), and they were not investigated further. The butanol extract of $D$. viscosa yielded three fractions $(18,19$ and 20) with moderate antibacterial activity, i.e., 50\%-75\% reduction in bacterial growth. In contrast, six fractions from the hexane extract inhibited $S$. aureus, with this antibacterial activity resulting in higher than $75 \%$ reduction in bacterial activity (Figure 1).

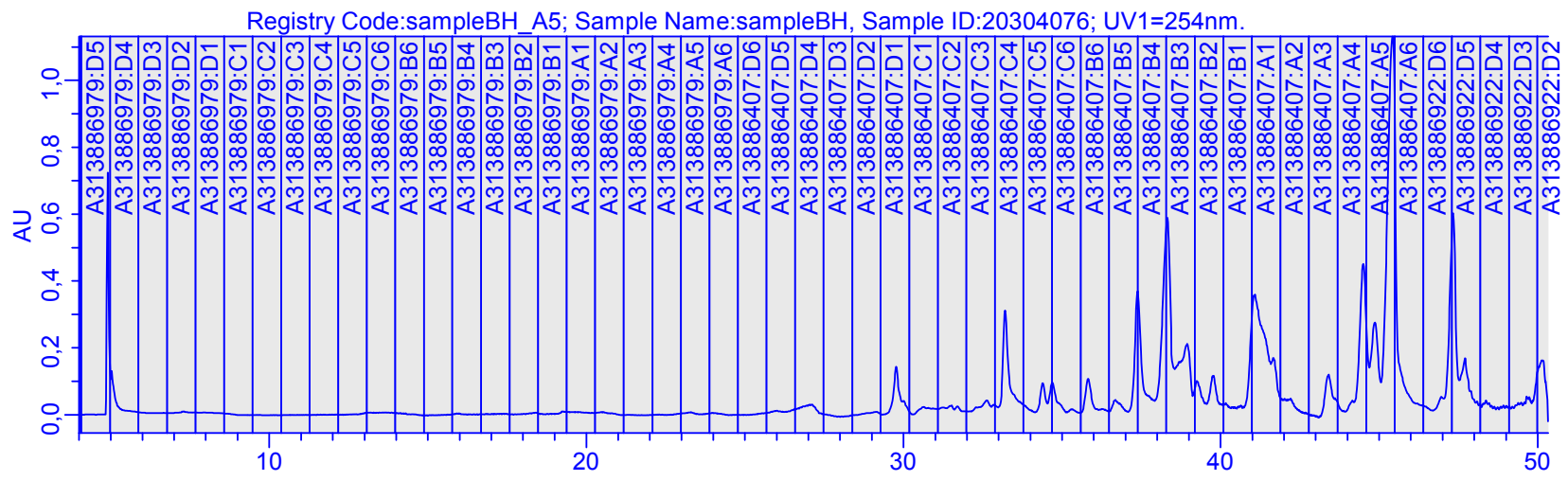

(a)

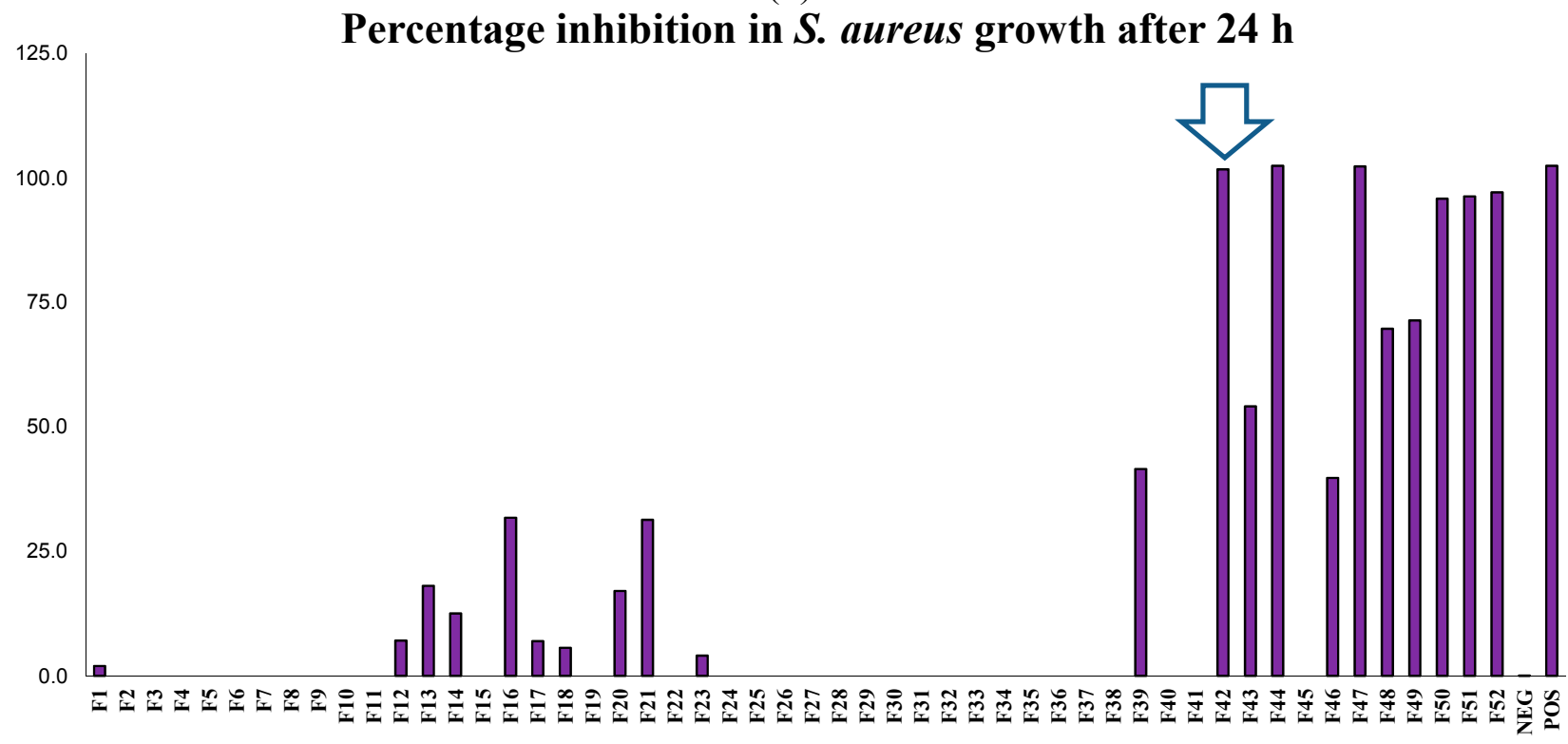

(b)

Figure 1. Cont. 


\section{Percentage inhibition in $E$. coli growth after $24 \mathrm{~h}$}

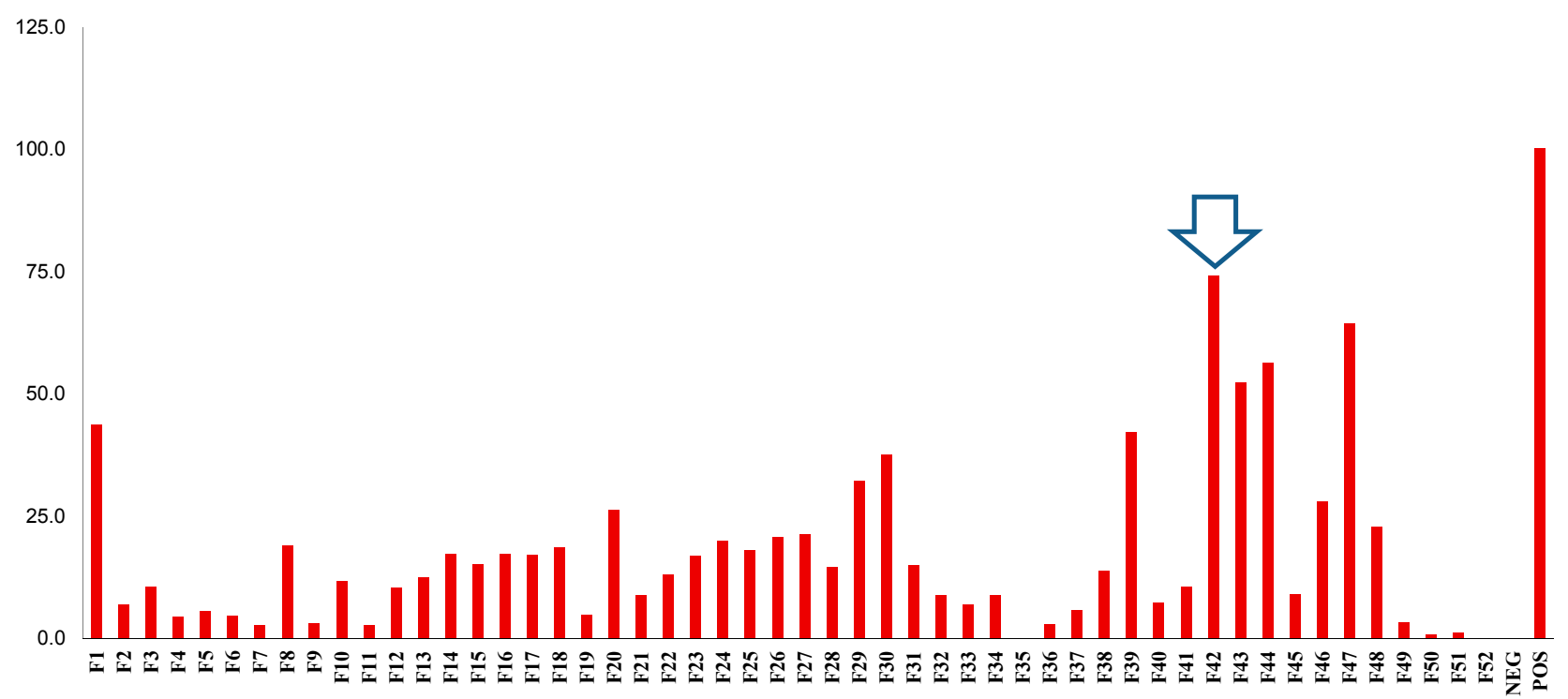

(c)

Figure 1. Preparative separation of $n$-hexane extract of $D$. viscosa using generic gradient and volume-based fractionation (a), percentage inhibition (b) of S. aureus (NCIMB 6571), percentage inhibition (c) of E. coli (NCIMB 8797), where NEG represented the negative control of $10 \%(v / v)$ dimethyl sulfoxide in phosphate buffer saline (DMSO/PBS) and the positive controls (POS) of clarithromycin $(25 \mu \mathrm{g} / \mathrm{mL})$ and ciprofloxacin $(50 \mu \mathrm{g} / \mathrm{mL})$, respectively ( $n=2 \pm \mathrm{SD}$ ). Fraction 42 (arrow) contained high purity, bioactive compound. XTT (2,3-bis(2-methoxy-4-nitro-5-sulfophenyl)-2H-tetrazolium-5-carboxanilide) Bioassay results are depicted in Figure $\mathrm{S} 1$.

Figure 2 shows the data from the preparative HPLC and the results of XTT assay, correlating with the active fractions to the corresponding peaks in the chromatogram and indicating the hydrophobic components of the fractions. Even if fractions with antibacterial activity were clearly evident, the majority of fractions enhanced bacterial viability (fractions with no inhibition), most likely due to additional carbon sources.

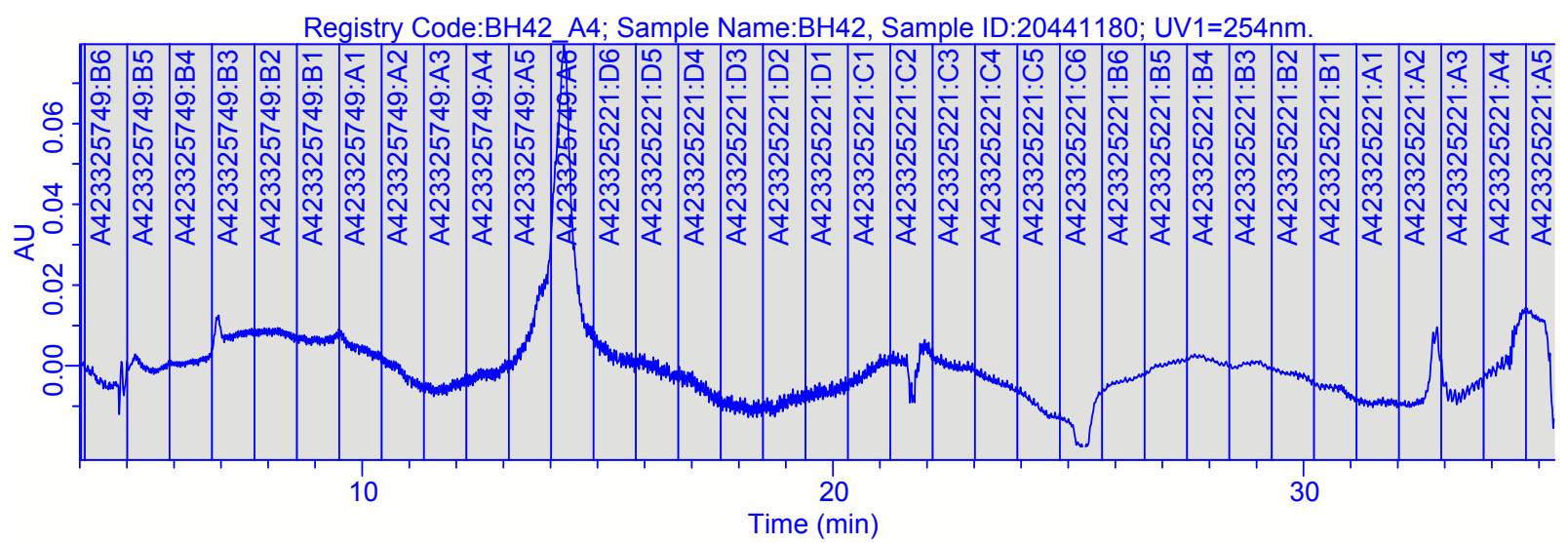

(a)

Figure 2. Cont. 
Percentage inhibition in $S$. aureus growth after $24 \mathrm{~h}$

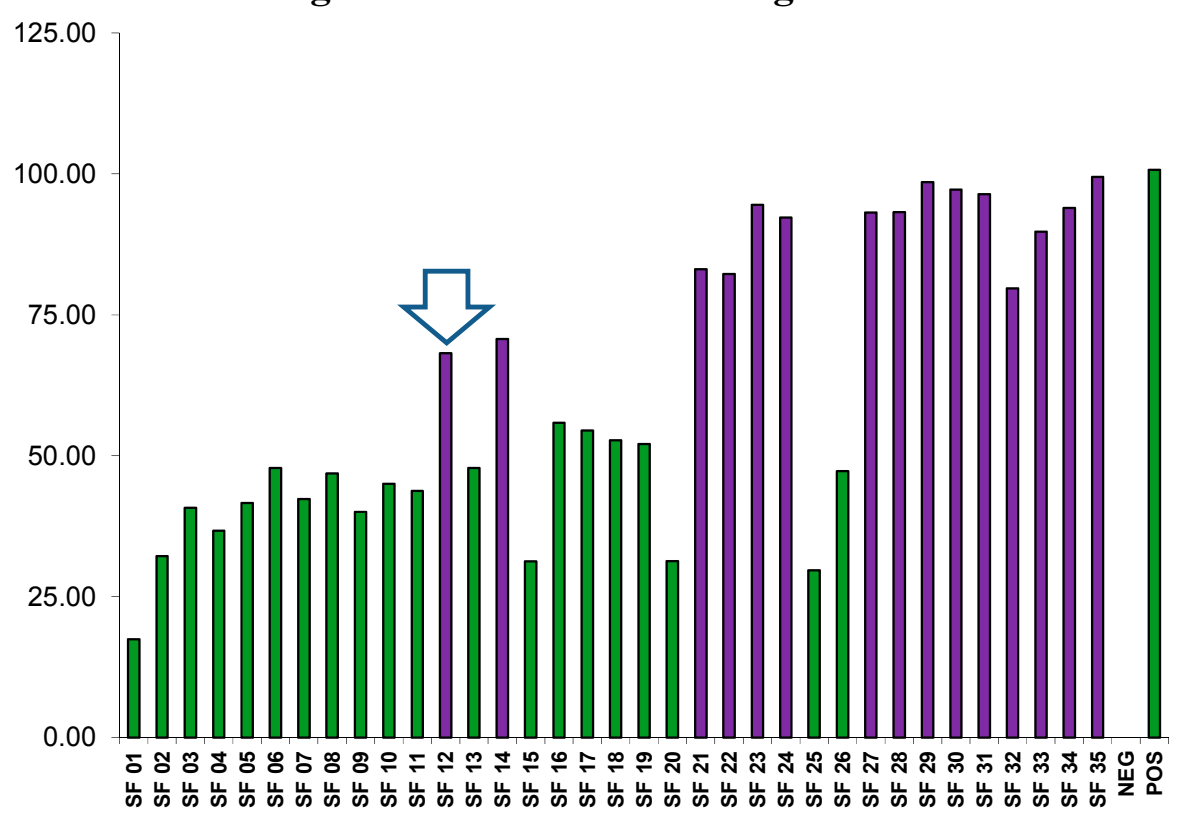

(b)

Percentage inhibtion in $E$. coli growth after $24 \mathrm{~h}$

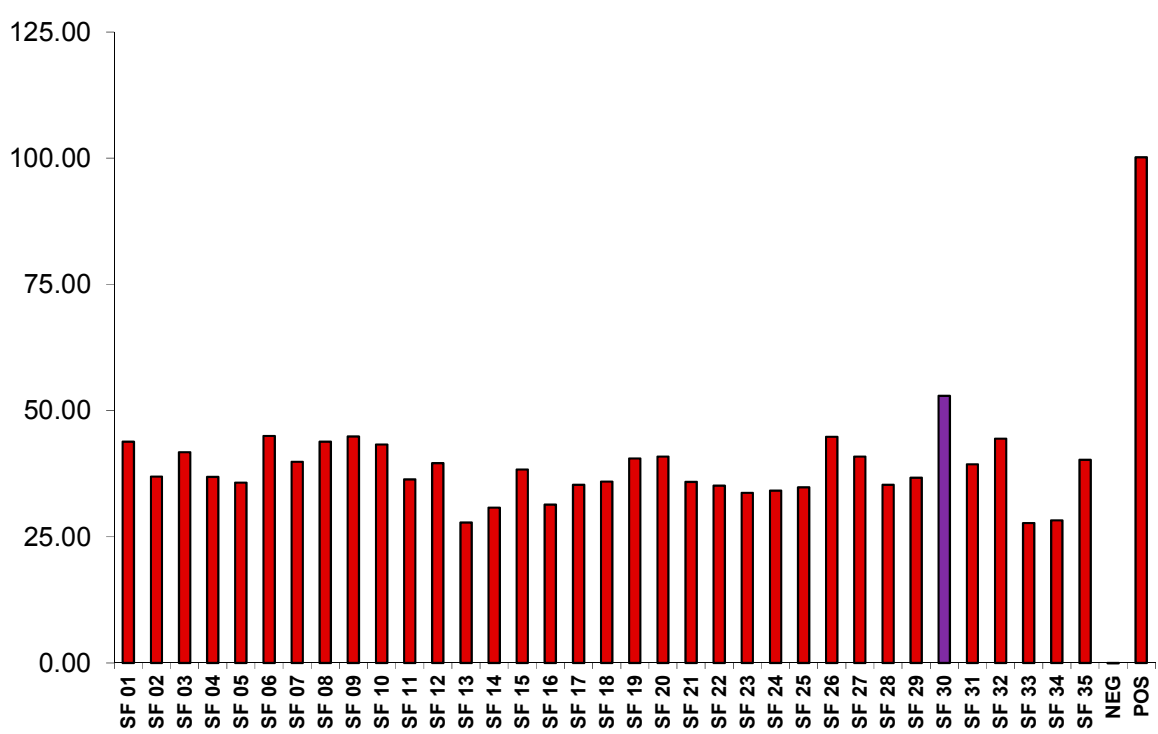

(c)

Figure 2. Separation and fractionation of bioactive fraction 42 from $n$-hexane extract of D. viscosa using polarity focused gradient (a) percentage inhibition (b) of $S$. aureus (NCIMB 6571), percentage inhibition (c) of E. coli (NCIMB 8797), where NEG represented the negative control of $10 \%(v / v)$ DMSO/PBS and POS the positive controls of clarithromycin $(25 \mu \mathrm{g} / \mathrm{mL})$ and ciprofloxacin $(50 \mu \mathrm{g} / \mathrm{mL})$ respectively, $(n=2 \pm \mathrm{SD})$. Fraction 12 (arrow) contained high purity, bioactive compound. XTT Bioassay results are depicted in Figure S2.

\subsection{Focused Gradients-XTT Bioassay}

Nine bioactive fractions from $D$. viscosa were further purified using focused gradients and each of the separated fractions were screened by the rapid XTT assay. The five primary fractions from the 
hexane extract from D. viscosa resulted in 22 fractions, which inhibited growth of S. aureus, and out of which 18 were as active as the positive control clarithromycin.

The combination of preparative HPLC with the XTT assay enabled the rapid isolation of bioactive fractions from plant extracts. In addition, after purification, information on purity and physicochemical properties of bioactive fractions were obtained by LC/MS analysis. Data from the XTT assay (Figure 2) and LC/MS analysis (Figure 3) led to focusing on one compound from D. viscosa. Though this information alone was not sufficient for full characterization of the compound, it provided essential information for monitoring, purifications and obtaining higher amounts of compounds, thus avoiding unnecessary bioassays.

The prime objective of these combination bioassays was to identify fractions with antibacterial activity. At the preliminary stages (fractions and sub-fractions level) quantification was not considered necessary with the reason that synergism and/or potentiation may exist between the respective metabolites that exist in a particular fraction, therefore, during initial screening, fractions were analysed on a qualitative basis. Activity was quantified when a purified bioactive metabolite was obtained.

The antibacterial compound 1 (Figure 4) from D. viscosa found in fractions H42 and sub-fraction 12 was purified and its structure was elucidated using the latest spectroscopic techniques including 1D and 2D NMR spectra (Table 2). Compound $\mathbf{1}$ was isolated as a white crystalline solid and showed single absorption in $\mathrm{UV}$ at $217.7 \mathrm{~nm}$. Its molecular formula was established as $\mathrm{C}_{20} \mathrm{H}_{28} \mathrm{O}_{4}$ by its EI-MS molecular ion peak at $\mathrm{m} / \mathrm{z} 332.1879$ (calculated (calcd.) for $\mathrm{C}_{20} \mathrm{H}_{28} \mathrm{O}_{4}, 332.2013$ ). Other major peaks appeared at $m / z 314.9$ (loss of $\mathrm{H}_{2} \mathrm{O}$ ) and at $\mathrm{m} / z 270.4$ (loss of $\mathrm{H}_{2} \mathrm{O}$ and $\mathrm{CO}_{2}$ ). The ${ }^{1} \mathrm{H}-\mathrm{NMR}$ spectrum displayed signals assignable to an unsaturated decalin system as $\delta=6.86(1 \mathrm{H}, \mathrm{dd}, J=2.9,4.6 \mathrm{~Hz}$ (H-3)), $1.22(3 \mathrm{H}, \mathrm{s}, \mathrm{H}-17), 0.87(3 \mathrm{H}, \mathrm{d}, J=6.8 \mathrm{~Hz}(\mathrm{H}-18))$ and $0.76(3 \mathrm{H}, \mathrm{s}, \mathrm{H}-20)$. Furthermore, the signals of a furane moiety appeared at $\delta=6.30(1 \mathrm{H}, \mathrm{brs}, \mathrm{H}-14), 7.38(1 \mathrm{H}, \mathrm{t}, J=0.8 \mathrm{~Hz}, \mathrm{H}-16)$ and 7.27 $(1 \mathrm{H}$, brs, $\mathrm{H}-15)$ respectively. In addition, the ${ }^{1} \mathrm{H}-\mathrm{NMR}$ spectrum showed signals at $\delta=3.64(1 \mathrm{H}$, dd, $J=10.8 \mathrm{~Hz}, 5.1 \mathrm{~Hz}(\mathrm{H}-6)$ ), which was assigned to Carbon 6 in the structure. ${ }^{1} \mathrm{H}-{ }^{1} \mathrm{H}$ COSY (Correlation Spectroscopy) experiments confirmed the C-6 proton by vicinal coupling cross peaks to both methylene protons of C-7. ${ }^{13} \mathrm{C}-\mathrm{NMR}$ spectrum revealed twenty carbon signals including six olefinic carbons at $\delta_{\mathrm{C}} 143.2$ (C-15), $111.1(\mathrm{C}-14), 141.9$ (C-4), 140.6 (C-3), 139 (C-16) and 125.9 (C-13) while the acid carbonyl carbon $(\mathrm{C}-18)$ resonated downfield at $\delta_{\mathrm{C}} 174.1$. In the DEPT (Distortionless Enhancement by Polarization Transfer) experiment among 20 carbons, three methyl, five methylene, seven methine and five quaternary carbons were distinguished. Further correlations in structure were made through HSQC (Heteronuclear Single Quantum Coherence) and HMBC (Heteronuclear Multiple Bond Correlation) experiments (Table 2). The spectral data was in complete agreement with $6 \beta$-hydroxy-15,16-epoxy-5 $\beta, 8 \beta, 9 \beta, 10 \alpha$-cleroda-3, 13(16), 14-trien-18-oic acid, the known compound in literature [14]. 
defaultile

MSAMB

$225 \mathrm{e}$

$2.0 \mathrm{e}+$

$1.75 \mathrm{e}+$

$\frac{12}{2}$

২

(a)

24-Nov-2008

17:01:26

2. Diode Antay Range: $2401 \mathrm{e}+1$

23.42

(b)

7.5 章

2.5年 1.43

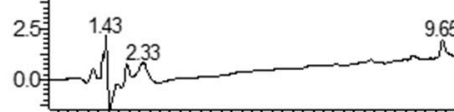
65 (13.03

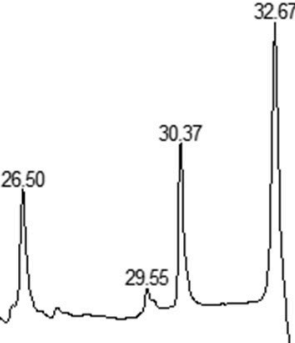

500
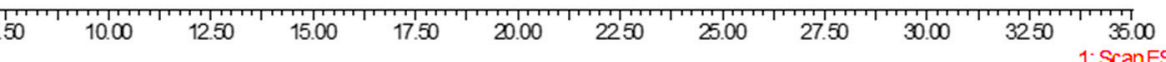

)

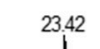

TIC
$3.1 \& 7$

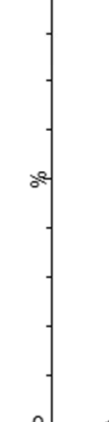

AD9

(c)

27-Van-2009

21:58:15

19.37 Range $4.747 \mathrm{e}+1$

$4.5 \mathrm{e}+1$
$4.0 \mathrm{e}+1$
$3.5 \mathrm{e}+1$
$3.0 \mathrm{e}+1$
$2.5 \mathrm{e}+1$
$2.0 \mathrm{e}+1$
$1.5 \mathrm{e}+1$
$1.0 \mathrm{e}+1$
5.0
0.0

AD9

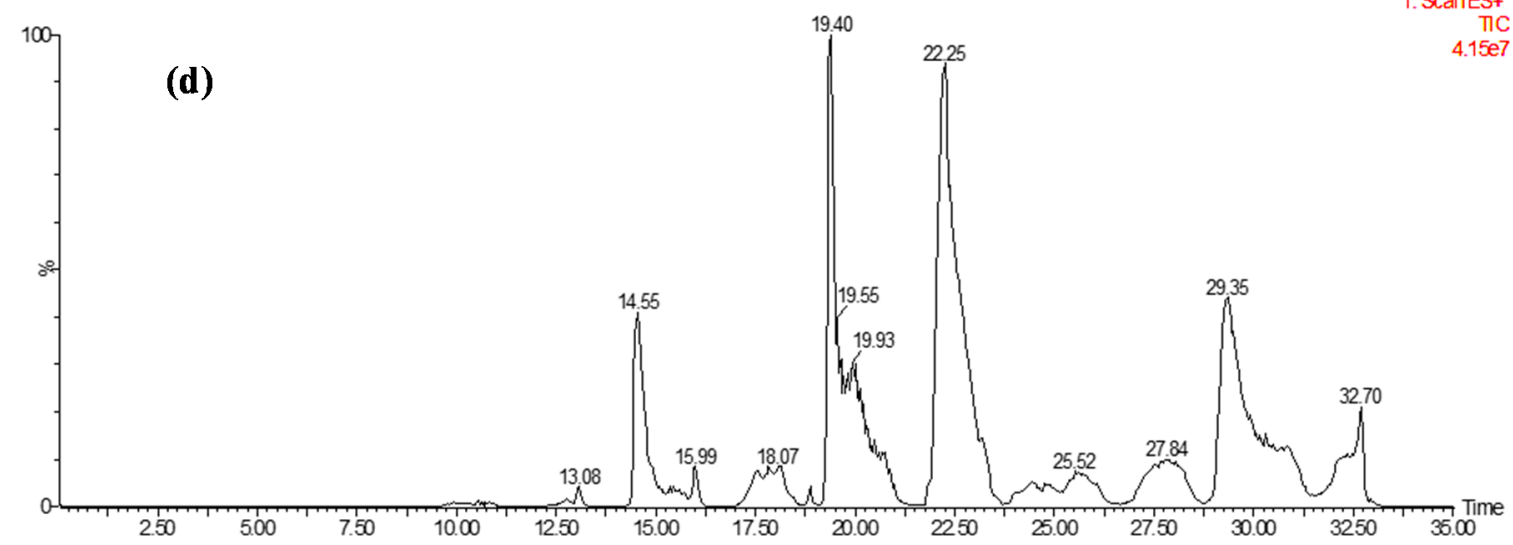

Figure 3. Cont. 


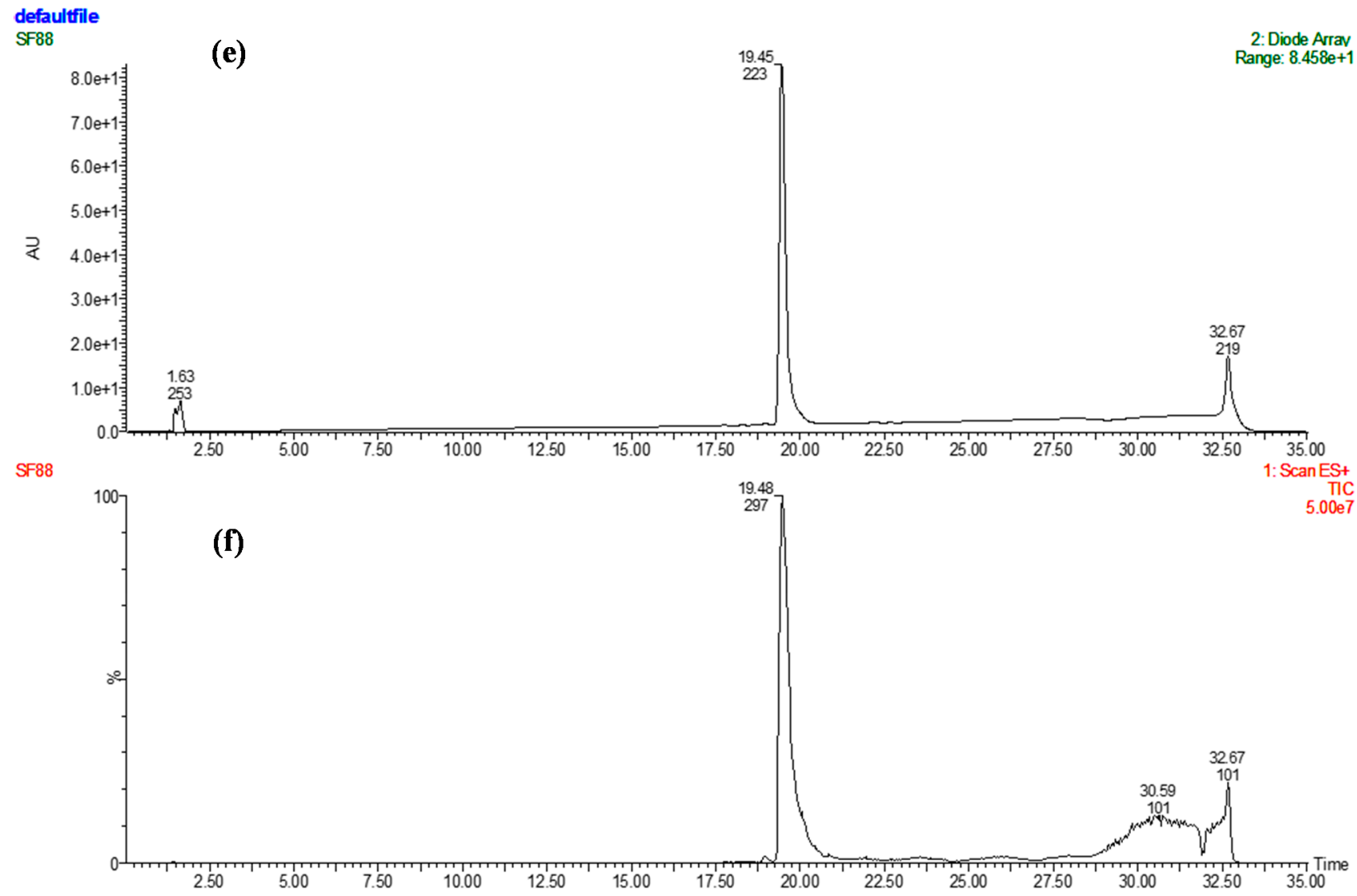

Figure 3. (a) Separation (photodiode array detector (PDA) chromatogram) of crude hexane D. viscosa extract by reversed phase HPLC; (b) Separation (MS chromatogram) of crude hexane D. viscosa extract by reversed phase HPLC; (c) bioactive fraction 42 (PDA chromatogram) from generic preparative separation; (d) bioactive fraction 42 (MS chromatogram) from generic preparative separation; (e) bioactive fraction 12 (PDA chromatogram) from polarity focused separation; (f) bioactive fraction 12 (MS chromatogram) from polarity focused separation.

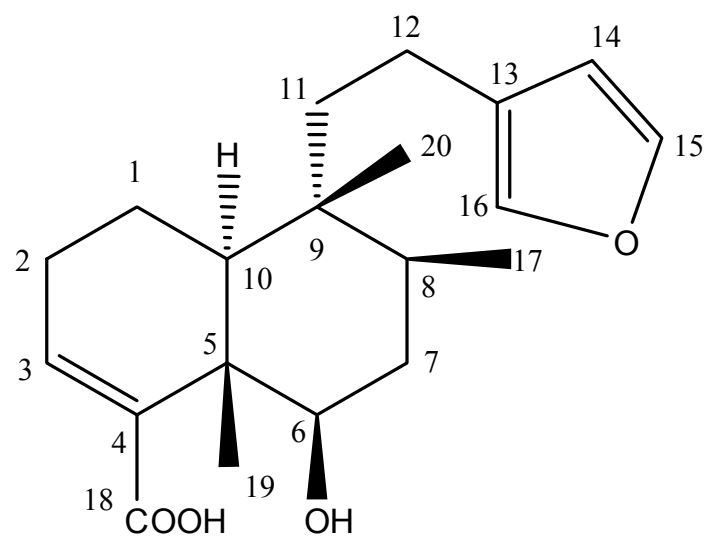

Figure 4. Chemical structure of compound 1 from D. viscosa. 
Table 2. ${ }^{13} \mathrm{C}$ - and ${ }^{1} \mathrm{H}-\mathrm{NMR}$ spectral data (methanol- $d_{4}$ ) and ${ }^{1} \mathrm{H} /{ }^{13} \mathrm{C}$ correlations of compound $\mathbf{1}$.

\begin{tabular}{|c|c|c|c|c|}
\hline $\begin{array}{l}\text { C. } \\
\text { No } \\
\end{array}$ & $\begin{array}{c}{ }^{13} \mathrm{C}-\mathrm{NMR} \\
(\delta) \\
\end{array}$ & $\begin{array}{c}\text { Multiplicity } \\
\text { DEPT }\end{array}$ & ${ }^{1} \mathrm{H}-\mathrm{NMR}(\delta)$ & ${ }^{1} \mathrm{H} /{ }^{13} \mathrm{C}$ (HMBC) Connectivity \\
\hline 1 & 17.5 & $\mathrm{CH}_{2}$ & $\alpha 1.75(\mathrm{~m}) \beta 1.65(\mathrm{~m})$ & H-3 (6.86) \\
\hline 2 & 27.4 & $\mathrm{CH}_{2}$ & $2.33(\mathrm{~m})$ & H-3 (6.86), H-10 (1.40) \\
\hline 3 & 140.6 & $\mathrm{CH}$ & $6.86(\mathrm{dd}, 2.9,4.6)$ & $\mathrm{H}-2$ (2.33), $\mathrm{H}_{\alpha}-1$ (1.75), $\mathrm{H}_{\beta}-1$ (1.65) \\
\hline 4 & 141.9 & $\mathrm{C}$ & - & H-3 (6.86), H-6 (3.64), H-17 (1.22) \\
\hline 5 & 45.1 & $\mathrm{C}$ & - & H-3 (6.86), H-17 (1.22) \\
\hline 6 & 75.2 & $\mathrm{CH}$ & $3.64(\mathrm{dd}, 5.1,10.8)$ & $\mathrm{H}-17(1.22)$ \\
\hline 7 & 36.4 & $\mathrm{CH}_{2}$ & $1.60(\mathrm{~m})$ & - \\
\hline 8 & 34.4 & $\mathrm{CH}$ & $1.76(\mathrm{~m})$ & H-18 (0.87), H-19 (0.76) \\
\hline 9 & 39.3 & $\mathrm{C}$ & - & H-18 $(0.87)$ \\
\hline 10 & 46.2 & $\mathrm{CH}$ & $1.40(\mathrm{bd}, 12.0)$ & $\mathrm{H}-19(0.76)$ \\
\hline 11 & 39.0 & $\mathrm{CH}_{2}$ & $1.61(\mathrm{~m})$ & H-10 (1.40), H-20 (0.76) \\
\hline 12 & 18.0 & $\mathrm{CH}_{2}$ & $2.30(\mathrm{~m})$ & $\mathrm{H}-19(0.76)$ \\
\hline 13 & 125.9 & $\mathrm{C}$ & - & $\mathrm{H}-12$ (2.30), H-14 (6.30), H-15 (7.38), H-16 (7.27) \\
\hline 14 & 111.1 & $\mathrm{CH}$ & $6.30(\mathrm{bs})$ & $\mathrm{H}-15(7.38), \mathrm{H}-16(7.27)$ \\
\hline 15 & 143.2 & $\mathrm{CH}$ & $7.38(t, 1.8)$ & $\mathrm{H}-14$ (6.30), H-16 (7.27) \\
\hline 16 & 139.0 & $\mathrm{CH}$ & 7.27 (bs) & H-12 (2.30), H-14 (6.30), H-15 (7.38) \\
\hline 17 & 15.2 & $\mathrm{CH}_{3}$ & $0.87(\mathrm{~d}, 6.8)$ & - \\
\hline 18 & 174.1 & $\mathrm{C}$ & - & - \\
\hline 19 & 16.1 & $\mathrm{CH}_{3}$ & $1.22(\mathrm{~s})$ & H-6 (3.64) \\
\hline 20 & 17.4 & $\mathrm{CH}_{3}$ & $0.76(\mathrm{~s})$ & - \\
\hline
\end{tabular}

2.6. MIC (Minimum Inhibitory Concentration) and MBC (Minimum Bactericidal Concentration) of Compound 1

The antibacterial activity of the compound $\mathbf{1}$ was quantified by evaluating the MIC (minimum inhibitory concentration) and MBC (minimum bactericidal concentration) against $S$. aureus (NCIMB 6571) and E. coli (NCIMB 8797). The results indicated a higher activity against S. aureus compared to $E$. coli, thereby suggesting it to be more effective against Gram-positive bacteria (Table 3 and Figure 5). The compound was crystalline, white coloured and soluble in 10\% (v/v) DMSO in PBS solution and, hence, no color interference was reported with the XTT assay.

Table 3. MIC (minimum inhibitory concentration) and MBC (minimum bactericidal concentration) of compound $\mathbf{1}$ isolated from D. viscosa against $S$. aureus and E. coli.

\begin{tabular}{ccccccc}
\hline \multirow{2}{*}{ Bacterial Susceptibility Assays } & \multicolumn{3}{c}{ Compound 1 } & \multicolumn{2}{c}{ Clarithromycin } & \multicolumn{2}{c}{ Ciprofloxacin } \\
\cline { 2 - 7 } & S. aureus & E. coli & S. aureus & E. coli & S. aureus & E. coli \\
\hline MIC $(\mu \mathrm{g} / \mathrm{mL})$ & 64 & 128 & 25 & - & - & 25 \\
$\mathrm{MBC}(\mu \mathrm{g} / \mathrm{mL})$ & 128 & 256 & 50 & - & - & 50 \\
\hline & $10 \%(v / v)$ & DMSO in PBS served as negative control.
\end{tabular}

A few Clerodane furanolactones and diterpenoid derivatives were previously identified in the liverwort Scapania nemorae [15], Solidago spp. [16] and in Aristeguetia spp. [17]. However, to the best of our knowledge, this is the first report on its antibacterial activity. Previously, five clerodane 
diterpenoids isolated from Pulicaria wightiana showed antibacterial activity against Bacillus subtilis, B. sphaericus, S. aureus, Klebsiella aerogenes and Chromobacterium violaceum [18]. The results obtained from the bio-guided isolation of furanyl clerodanoic acid in D. viscosa, as well as the antimicrobial activity of hautriwaic acid, a D. viscosa component, reported to be active against B. subtilis, S. aureus and E. coli [8], support the possible use of this plant for the treatment of infectious diseases in the traditional systems of medicines. The application of the XTT bioassay in identification of bioactive metabolite and quantification of its antibacterial activity using standard test bacteria provides an approach that may be utilized in similar kinds of experiments. Since, in case of plant extracts, the commonly utilized assays (agar well diffusion and disk diffusion assays) that only highlight the antimicrobial activity of extracts or their fractions do not demonstrate the actual potential of that particular plant, more detailed standardized assays are essential. Moreover, the potential of isolated compounds can be easily quantified through MIC assays using the XTT bioassay-based approach.
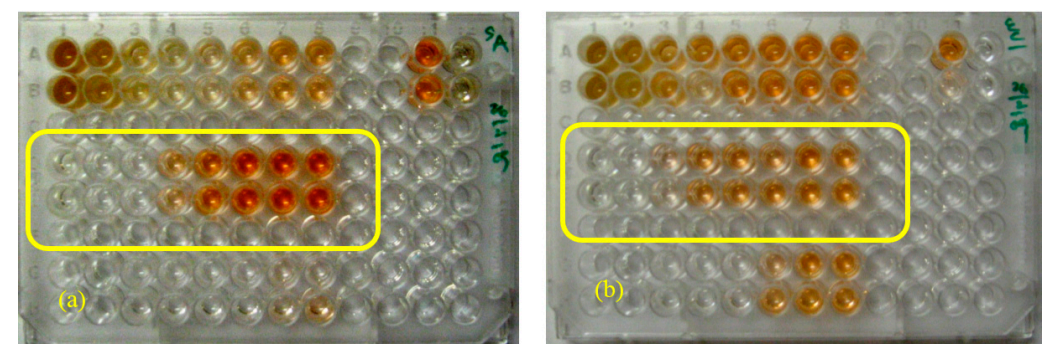

Figure 5. MICs of compound 1 (in yellow rectangle) isolated from D. viscosa against S. aureus (a) and E. coli (b).

The isolated compound belongs to isoprenoids that are known to possess antimicrobial activity. In general, Gram-positive bacteria are more susceptible to these compounds, as confirmed by our results. Putative mechanisms of action may include cell membrane disruption, alteration in the cell membrane fluidity and permeability, increased susceptibility to antibiotics, and disturbances in the respiration chain due to modification of membrane-bound protein localization [19]. Moreover, isoprenoids may also be considered for adjuvant therapy with conventional antimicrobials, in order to reduce, delay or impair antibiotic resistance. Studies on antibiotic activity of clerodane type diterpenoid on other microorganisms are still in progress, and further investigations on its possible mechanism(s) of action will be planned and designed.

\section{Experimental Section}

\subsection{Chemicals}

Dichloromethane, $n$-hexane, ethyl acetate and $n$-butanol were obtained from Merck (Darmstadt, Germany). Acetonitrile and methanol (HPLC grade) were obtained from Rathburn (Walkerburn, Scotland). Trifluoroacetic acid (TFA) and dimethyl sulfoxide (DMSO) were from Fisher (Loughborough, UK). Milli-Q system (Millipore, Watford, UK) was used for water purification. XTT sodium salt, menadione sodium bisulfite (2-methyl-1,4-naphthoquinone sodium bisulfite), ciprofloxacin and clarithromycin were from Sigma (Poole, UK). Nutrient broth and agar, Mueller-Hinton agar and phosphate buffered saline (PBS) were from Oxoid (Fisher, Loughborough, UK). 


\subsection{Bacterial Strains}

Preliminary screening and XTT bioassays were carried using E. coli (NCIMB 8797) and S. aureus (NCIMB 6571) obtained from the National Collection of Industrial, Marine and Food Bacteria (NCIMB; Aberdeen, UK).

\subsection{Plant Material and Extraction Procedures}

Dodonaea viscosa (L.) Jaeq. belongs to the Sapindaceae family. The aerial parts of the plant (Figure 6) were collected from Kohat, Khyber Pakhtoonkhwa (formerly North West Frontier Province; (NWFP)) (Latitude $33^{\circ} 19^{\prime} 59^{\prime \prime}$ and Longitude $71^{\circ} 10^{\prime} 0^{\prime \prime}$ ) Pakistan, in September 2007. A specimen was matched for confirmation of identity with the reference voucher number 592, preserved in the Herbarium of Pakistan (Quaid-i-Azam University, Islamabad, Pakistan). Shade-dried aerial parts (leaves and stems weighing $9 \mathrm{~kg})$ of $D$. viscosa were ground to a fine powder and extracted with ethanol $(80 \% \mathrm{v} / \mathrm{v})$. The pulverized material was filtered using Whatman No. $1(460 \times 570 \mathrm{~mm}$; approximately $11 \mu \mathrm{m}$ pore size) in a percolator. Temperature during processing was maintained below $30{ }^{\circ} \mathrm{C}$. Three portions of the percolate were collected at intervals of $96 \mathrm{~h}$ finally resulting in $11 \mathrm{~L}$ of extract. The ethanol was evaporated using a rotary evaporator (Buchi, Flawil, Switzerland) to give $2.5 \mathrm{~L}$ of crude extract. Crude aqueous fraction was sequentially partitioned with $n$-hexane $(3 \times 1 \mathrm{~L})$, dichloromethane $(3 \times 1 \mathrm{~L})$, ethyl acetate $(3 \times 1 \mathrm{~L})$ and $n$-butanol $(3 \times 1 \mathrm{~L})$ and combined extractions were dried by rotary evaporation [20].

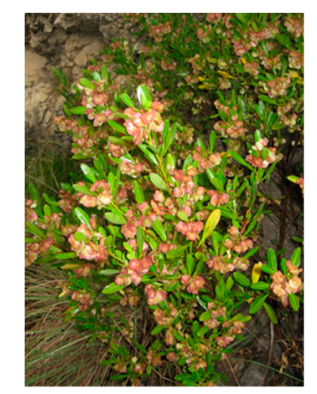

Figure 6. Dodonaea viscosa (L.) Jaeq., Florida Hopbush, Hopbush, Varnish plant, Ghwaraskay (Pushto), Vilayeti-mehndi (Hindi; Urdu).

\subsection{Chemical Characterization}

\subsubsection{Preparative HPLC}

Preparative HPLC was performed using a Biotage Parallex Flex (Biotage, Cardiff, UK) where Flex V3 software was used for instrument control and data acquisition. Separations were performed on a Hyperprep HS C18 column (10 mm I.D. (internal diameter) $\times 150 \mathrm{~mm}$ long; $8 \mu \mathrm{m}$ particle size; Thermo scientific, Cheshire, UK) with a pre column (KR 100-13 C18-10 CP; Hichrom Ltd., Berkshire, UK). Mobile phase included Milli-Q water (A), and methanol (B). The crude samples were separated using a gradient increasing from $10 \%$ to $100 \% \mathrm{~B}$ over $50 \mathrm{~min}$ at a flow rate of $10 \mathrm{~mL} / \mathrm{min}$. The concentration of crude fractions was $0.2 \mathrm{~g} / \mathrm{mL}$, and each injection volume was $0.25 \mathrm{~mL}$. Eluent was monitored at 220 and $254 \mathrm{~nm}$ and fractionation was volume-based, collecting $9 \mathrm{~mL}$ fractions into deep 
well microtitre plates $(24 \times 10 \mathrm{~mL}$; Whatman, Kent, UK). The butanol extract of $D$. viscosa had three fractions (18, 19 and 20) with moderate antibacterial activity (50\%-75\% reduction in bacterial growth), while six fractions from the hexane extract inhibited only $S$. aureus $(>75 \%$ reduction in bacterial activity) (Figure 2 and Table 2). Using the data available on the percentage of methanol eluting the bioactive fractions, shorter $(30 \mathrm{~min}$ ) focused gradients were selected for further purification of all the primary bioactive fractions, as summarized for each fraction in Table 4.

Table 4. Bioactive fractions from extracts of $D$. viscosa separated by preparative HPLC.

\begin{tabular}{|c|c|c|}
\hline Sample_Fraction (mg Dry Weight) & Percentage Methanol & Focused Gradient \\
\hline D. viscosa-B $18^{\mathrm{a}}(1.0)$ & 42 & \\
\hline D. viscosa-B19 (2.2) & 43 & $25 \%-55 \%$ methanol \\
\hline D. viscosa-B20 (5.9) & 45 & \\
\hline D. viscosa-H42 ${ }^{\mathrm{b}}(1.9)$ & 83 & \\
\hline D. viscosa-H44 (2.9) & 86 & \\
\hline D. viscosa-H47 (1.6) & 91 & $80 \%-100 \%$ \\
\hline D. viscosa-H50 (1.1) & 97 & \\
\hline D. viscosa-H51 (1.0) & 98 & \\
\hline D. viscosa-H52 (1.6) & 100 & $80 \%-100 \%$ and hold for $10 \mathrm{~min}$ \\
\hline
\end{tabular}

Focused Separation of Bioactive Fractions

Fractions from the generic separations that exhibited antibacterial activity were dried, weighed and re-dissolved in $0.5 \mathrm{~mL}$ methanol. These were further purified using polarity focused gradients based on the proportion of methanol in which they were eluted during the generic gradient (Table 2). Column and solvents were as described in Section 3.4.1 with an injection volume of $0.25 \mathrm{~mL}$. Fraction collection was based on volume ( $9 \mathrm{~mL}$ fraction).

A total of nine bioactive fractions from $D$. viscosa were further purified using focused gradients over $30 \mathrm{~min}$. Each separation resulted in 35 fractions which were screened by the rapid XTT assay (Figure 2). The five primary fractions from the hexane extract from D. viscosa resulted in 22 fractions (Table 5) which inhibited $S$. aureus, out of 18 as active as to the positive control clarithromycin, indicating the potential of this plant as a source of new drugs or drug scaffolds. Slight or no activity was observed in E. coli (Figure 2).

Table 5. Summary of bioactive sub-fractions from focused preparative HPLC runs of fractions from $D$. viscosa hexane fraction.

\begin{tabular}{cc}
\hline Sample-Primary Fraction & Sub-Fraction \\
\hline D. viscos $a-\mathrm{H} 42$ & $12,14,21-24,29,30$ \\
D. viscos $a-\mathrm{H} 44$ & 15,17 \\
D. viscosa-H50 & $25-27$ \\
D. viscos $a-\mathrm{H} 51$ & $27-30$ \\
D. viscos $a-\mathrm{H} 52$ & $21,23,24,37,38$ \\
\hline
\end{tabular}




\subsubsection{Analytical HPLC}

The HPLC system consisted of a Waters Alliance 2695 with a 2996 photodiode array detector (PDA) and a ZQ 2000 mass spectrometer (Elstree, Hertfordshire, UK). A Sunfire C18 column (Length $150 \mathrm{~mm} \times 2.1 \mathrm{~mm}$ I.D., particle size $5 \mu \mathrm{m}$ ) which was maintained at $40{ }^{\circ} \mathrm{C}$ was used for separation. Mobile phase was Milli-Q water (A) and acetonitrile (B) both containing $0.05 \%$ TFA. A gradient increasing from $5 \%$ to $100 \% \mathrm{~B}$ over $30 \mathrm{~min}$ at a flow rate of $0.3 \mathrm{~mL} / \mathrm{min}$ was used for separation of samples $(10 \mu \mathrm{L})$. Eluent was monitored from 210 to $400 \mathrm{~nm}$ with a resolution $1.2 \mathrm{~nm}$ and by positive ion electrospray (ESI+) in series, scanning from $\mathrm{m} / \mathrm{z} 100$ to 1600 with a scan time of $2 \mathrm{~s}$ and inter-scan delay of $0.1 \mathrm{~s}$. Ion source parameters: Sprayer voltage, $3.07 \mathrm{KV}$; cone voltage, $40 \mathrm{~V}$; desolvation temperature, $300{ }^{\circ} \mathrm{C}$; source temperature, $100{ }^{\circ} \mathrm{C}$. Instrument control, data acquisition and processing were done using MassLynx v4.1 (Waters, Elstree, Hertfordshire, UK). The active component in the $n$-hexane extract of D. viscosa was found in H42 (Figure 1) and sub-fraction 12 (Figure 2), where the relative purity (PDA-210 to $400 \mathrm{~nm}$ ) achieved was $>90 \%$ (Figure 3 ).

\subsubsection{Physical and Spectral Data for Compound 1}

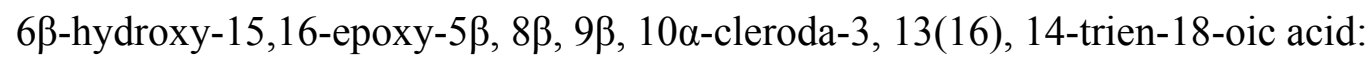

Crystalline solid $(20 \mathrm{mg})$ : UV $\left(\lambda_{\max }, \mathrm{MeOH}\right)=217.7 \mathrm{~nm}$. HR-EIMS $\mathrm{m} / z=332.1879$ (calcd. for $\left.\mathrm{C}_{20} \mathrm{H}_{28} \mathrm{O}_{4}, 332.2013\right)$. The ${ }^{1} \mathrm{H}-\mathrm{NMR}(400 \mathrm{MHz})$ and ${ }^{13} \mathrm{C}-\mathrm{NMR}$ (100 MHz) were recorded in MeOD- $d_{4}$ on a BRUKER Ultrashield 400 (Bruker UK Limited, Coventry, UK) (Table 2).

\subsection{Antibacterial Activity}

\subsubsection{Preliminary Antibacterial Screening}

Crude extracts $(16.7 \mathrm{mg} / \mathrm{mL})$ were re-suspended in methanol and sterilized using Millex, $33 \mathrm{~mm}$ filter $(0.22 \mu \mathrm{m}$ pore size; Millipore, Watford, UK). Aliquots $(6 \mu \mathrm{L})$ were applied to sterile disks (6 $\mathrm{mm}$ diameter punched from Whatman No. 1 filters). Negative control disks had same volume of methanol on each disk. Ciprofloxacin $(10 \mu \mathrm{g} / \mathrm{disk})$ and clarithromycin $(15 \mu \mathrm{g} / \mathrm{disk})$ served as the positive controls for E. coli NCIMB 8797 and S. aureus NCIMB 6571, respectively. The bacteria were kept on nutrient agar and fresh standardized inocula, turbidity equivalent to $0.5 \mathrm{McFarland}\left(\approx 1.5 \times 10^{8} \mathrm{CFU} / \mathrm{mL}\right)$ [21], were used for each experiment. Disks containing the crude extracts, negative control disks (methanol) and positive controls were aseptically placed on the seeded plates. Prior to overnight incubation at $37{ }^{\circ} \mathrm{C}$, seeded plates with disks were kept in inverted position in refrigerator for $2 \mathrm{~h}$ to allow adequate diffusion of extracts. All the tests were performed in triplicate.

\subsubsection{XTT Bioassay}

XTT solution $(1 \mathrm{mg} / \mathrm{mL})$ in PBS was prepared and sterilized using Millex, $33 \mathrm{~mm}$ filter $(0.22 \mu \mathrm{m}$ pore size; Millipore, Watford, UK) and stored at $-80{ }^{\circ} \mathrm{C}$ in cryotubes (Cole-Parmer, London, UK) until use. Menadione $(173 \mu \mathrm{g} / \mathrm{mL})$ in acetone was prepared fresh before to every assay. XTT aliquots were thawed at room temperature and, then, menadione was added to XTT (1:12). From each fraction collected during prep-HPLC, an aliquot $(300 \mu \mathrm{L})$ was placed in glass vials $(2 \mathrm{~mL}$; Alltech, Carnforth, 
UK) and dried overnight in a laminar flow cabinet and re-suspended in 10\% $v / v$ DMSO/PBS (400 $\mu \mathrm{L})$ [22]. Samples $(100 \mu \mathrm{L})$ were transferred into the wells of 96-well flat bottom microtiter plates (Sterilin, Aberbargoed, UK). E. coli NCIMB 8797 and S. aureus NCIMB 6571 inocula were prepared as mentioned earlier. Inoculum $(100 \mu \mathrm{L})$ of each test bacteria was added to each of the test well, into negative control (DMSO/PBS) and positive control (ciprofloxacin for E. coli, and clarithromycin for S. aureus) wells. XTT/menadione mixture $(18 \mu \mathrm{L})$ was added to each test well and plates were gently shaken. Absorbance at $490 \mathrm{~nm}$ was recorded using a BioTek microplate reader (Fisher, Loughborough, UK) at the start of the test and after overnight incubation at $37{ }^{\circ} \mathrm{C}$. All tests were performed in duplicate. Percent increase in absorbance $(\mathrm{X})$ was calculated using formula 1 , where $A_{t N}$ and $A_{t 0}$ represented mean absorbance values after $24 \mathrm{~h}$ incubation and at the start of test, respectively. Similarly, percentage increase in negative control (N) was also calculated using Equation (1). Percent reduction $(\mathrm{R})$ in cell metabolism was calculated using Equation (2), where $\mathrm{X}_{\mathrm{N}}$ and $\mathrm{T}_{\mathrm{N}}$ represented percent increase in absorbance of test material and negative control, respectively, at time $(\mathrm{N})$ which was standardized at $24 \mathrm{~h}$.

$$
\begin{aligned}
& \mathrm{X}_{\mathrm{tN}}=\mathrm{A}_{\mathrm{tN}}-\mathrm{A}_{\mathrm{t} 0} / \mathrm{A}_{\mathrm{t} 0} \times 100 \\
& \mathrm{R}=100-\left(\left(\mathrm{X}_{\mathrm{N}} / \mathrm{T}_{\mathrm{N}}\right) \times 100\right)
\end{aligned}
$$

Fractions were considered to have an antibacterial effect when they gave a mean $(n=2)$ reduction in the XTT colorimetric bioassay of $\geq 50 \%$ (threshold level for antibacterial activity), and $<50 \%$ value was termed to have slight or no antibacterial activity $[13,23]$.

\section{Determination of Minimum Inhibitory Concentration (MIC) of Purified Compound}

MIC is defined as the lowest antimicrobial concentration that completely inhibits visible bacterial growth, as detected visually or via an automated or semiautomated method. One hundred $\mu \mathrm{L}$ of purified compound solution $(256 \mu \mathrm{g} / \mathrm{mL})$ in DMSO/PBS was transferred aseptically to the microtiter plates and, sequentially, half diluted in sterile solution of DMSO/PBS such that final dilution of $2 \mu \mathrm{g} / \mathrm{mL}$ was achieved. Then $100 \mu \mathrm{L}$ of standardized inoculum $\left(\approx 1.5 \times 10^{8} \mathrm{CFU} / \mathrm{mL}\right)$ was added to each of the test wells and into negative control (DMSO/PBS) and positive control (ciprofloxacin for E. coli and clarithromycin for $S$. aureus) containing wells. Then, to each test well, $18 \mu \mathrm{L}$ of XTT/menadione reagent were added and plates were gently shaken. Absorbance at $490 \mathrm{~nm}$ was recorded using microplate reader at the start of the test and, then, after $24 \mathrm{~h}$ of incubation at $37^{\circ} \mathrm{C}$. The tests were run in duplicate. The wells having no visible bacterial growth, detected visually and having no change in absorbance before and after $24 \mathrm{~h}$ of application of test defined the MIC of the compound.

\subsubsection{Determination of Minimum Bactericidal Concentration (MBC) of Purified Compound}

The MBC was defined as the concentration of the antimicrobial agent that results in the $99.9 \%$ reduction in $\mathrm{CFU} / \mathrm{mL}$, compared with the organism concentration in the original inocula. The plates used for the evaluation of MIC were utilized such that, after $24 \mathrm{~h}$ incubation, the wells that were visibly clear and showed no metabolic activity of bacteria, ascertained from the absorbance and \% reduction in bacterial population readings (evaluated using formulas given in Section 3.5.2.), were selected and $50 \mu \mathrm{L}$ aliquots from each well were spread separately on the entire surfaces of sterile 
nutrient agar plates with the help of sterile glass spreader, and incubated in inverted position overnight at $37^{\circ} \mathrm{C}$. The tests were run in duplicate. The aliquots of wells that gave no growth defined the MBC of the compound.

\section{Conclusions}

The combination of automated preparative HPLC with simple generic gradients followed by focused gradients combined with the XTT bioassay led to the identification of sub-fractions with slight antibacterial activity. This approach resulted in isolation of a clerodane type diterpenoid, $6 \beta$-hydroxy-

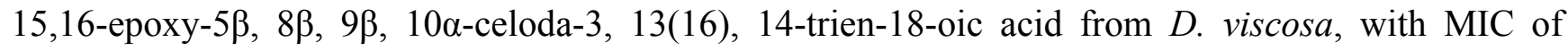
64 and $128 \mu \mathrm{g} / \mathrm{mL}$, and $\mathrm{MBC}$ of 64 and $256 \mu \mathrm{g} / \mathrm{mL}$ against $S$. aureus and E. coli, respectively. This supports the use of D. viscosa as antibacterial remedy in traditional systems of healing. Further evaluations of antibacterial spectrum are required. Although only one compound was isolated during this study, there were clearly several bioactive compounds which require further investigation. Moreover, the approach applied in identification and standardization of active metabolite can be capitalized in similar research.

\section{Supplementary Materials}

Supplementary materials can be found at http://www.mdpi.com/1422-0067/16/09/20290/s1.

\section{Acknowledgments}

The authors are grateful to the Royal Society of Edinburgh, UK and Higher Education Commission, Pakistan for providing funds to Muhammad Khurram. Thanks are also due to Marcel Jaspars, Chair in Chemistry, University of Aberdeen, for conduction of NMR experimentation. Support of Heather Scott and Mairi Thomson of The Robert Gordon University, Aberdeen for provision of bacterial strains and material support is acknowledged.

\section{Author Contributions}

Muhammad Khurram and Christine Edwards designed, performed the experiments and wrote the manuscript; Linda A. Lawton conceived and designed the experiments and contributed reagents/materials/ analysis tools and revised the manuscript; Marcello Iriti and Abdul Hameed contributed in data analysis, write up of paper; Farman A. Khan and Murad A. Khan performed the NMR interpretation; Shafiq ur Rahman analyzed the data and prepared the figures.

\section{Conflicts of Interest}

The authors declare no conflict of interest.

\section{References}

1. Fischbach, M.A.; Walsh, C.T. Antibiotics for emerging pathogens. Science 2009, 325, 1089-1093.

2. Rates, S.M.K. Plants as source of drugs. Toxicon 2001, 39, 603-613. 
3. Arun, M.; Asha, V.V. Gastroprotective effect of Dodonaea viscosa on various experimental ulcer models. J. Ethanopharmacol. 2008, 118, 460-465.

4. Pillay, P.; Maharaj, J.V.; Smith, J.P. Investigating South African plants as a source of new antimalarial drugs. J. Ethanopharmacol. 2008, 119, 438-454.

5. Srinivasan, D.; Nathan, S.; Suresh, T.; Perumalsamy, L.P. Antimicrobial activity of certain Indian medicinal plants used in folkloric medicine. J. Ethanopharmacol. 2001, 74, 217-220.

6. Getie, M.; Gebre-Mariam, T.; Rietz, R.; Hohne, C.; Huschka, C.; Schmidtke, M.; Abate, A.; Neubert, H.H.R. Evaluation of the anti-microbial and anti-inflammatory activities of the medicinal plants Dodonaea viscosa, Rumex nervosus and Rumex abyssinicus. Fitoterapia 2003, 74, 139-143.

7. Patel, M.; Coogan, M.M. Antifungal activity of the plant Dodonaea viscosa var. angustifolia on Candida albicans from HIV-infected patients. J. Ethanopharmacol. 2008, 118, 173-176.

8. Rojas, A.; Hernandez, L.; Pereda-Miranda, R.; Mata, R. Screening for antimicrobial activity of crude drug extracts and pure natural products from Mexican medicinal plants. J. Ethanopharmacol. 1992, 35, 275-283.

9. Eldridge, G.R.; Vervoot, H.C.; Lee, C.M.; Cremin, P.A.; Williams, C.T.; Hart, S.M.; Goering, M.G.; O'Neil-Johnson, M.; Zeng, L. High-throughput method for the production and analysis of large natural product libraries for drug discovery. Anal. Chem. 2002, 74, 3963-3971.

10. Tu, Y.; Jeffries, C.; Ruan, H.; Nelson, C.; Smithson, D.; Shelat, A.A.; Brown, K.M.; Li, X.; Hester, J.P.;Smillie, T.; et al. Automated high-throughput system to fractionate plant natural products for drug discovery. J. Nat. Prod. 2010, 73, 751-754.

11. Gabrielson, J.; Hart, M.; Jarelöv, A.; Kühn, I.; McKenzie, D.; Mölby, R. Evaluation of redox indicators and the use of digital scanners and spectrophotometer for quantification of microbial growth in microplates. J. Microbiol. Methods 2002, 50, 63-73.

12. Williams, C.; Espinosa, O.A.; Montenegro, H.; Cubilla, L.; Capson, T.L.; Ortega-Barria, E.; Romero, L.I. Hydrosoluble formazan XTT: Its application to natural products drug discovery for Leishmania. J. Microbiol. Methods 2003, 55, 813-816.

13. Al-Bakri, G.A.; Afifi, U.F. Evaluation of antimicrobial activity of selected plant extracts by rapid XTT colorimetry and bacterial enumeration. J. Microbiol. Methods 2007, 68, 19-25.

14. Anis, I.; Anis, E.; Ahmed, S.; Mustafa, G.; Malik, A.; Amtul, Z.; Atta-ur-Rahman. Thormbin inhibitory constituents from Duranta repens. Helv. Chim. Acta 2001, 84, 649-655.

15. Geis, W.; Buschauer, B.; Becker, H. cis-Clerodandes from axenic cultures of the liverwort Scapania nemorea. Phytochemistry 1999, 51, 643-649.

16. McCrindle, R.; Nakamura, E.; Anderson, B.A. Constituents of Solidago species. Part VII. Constitution and stereochemistry of the cis-clerodanes from Solidago arguta Ait. and of related diterpenoids. J. Chem. Soc. Perkins Trans. 1976, 1, 1590-1597.

17. Zdero, C.; Bohlmann, F.; King, M.R. Diterpenes and norditerpenes from the Aristeguetia group. Phytochemistry 1991, 30, 2991-3000.

18. Das, B.; Reddy, R.M.; Ramu, R.; Ravindranath, N.; Harish, H.; Ramakrishna, S.V. K.; Rao, K.Y.; Harakishore, K.; Murthy, N.S.U. Clerodane diterpenoids from Pulicaria wightiana. Phytochemistry 2005, 66, 633-638. 
19. Brehm-Stecher, F.B.; Johnson, A.E. Sensitization of Staphylococcus aureus and Escherichia coli to antibiotics by the sesquiterpenoids nerolidol, farnesol, bisabolol, and apritone. Antimicrob. Agents Chemother. 2003, 47, 3357-3360.

20. Khurram, M.; Khan, A.M.; Hameed, A.; Abbas, N.; Qayum, A.; Inayat, H. Antibacterial activities of Dodonaea viscosa using Contact Bioautography Technique. Molecules 2009, 14, 1332-1341.

21. Forbes, A.B.; Sahm, F.D.; Weissfeld, S.A. Bailey \& Scott's Diagnostic Microbiology, 10th ed.; Elsevier: St. Louis, MO, USA, 2007; p. 188.

22. Prabuseenivasan, S.; Jayakumar, M. Ignacimuthu, S. In vitro antibacterial activity of some plant essential oils. BMC Complement. Altern. Med. 2006, 6, 39, doi:10.1186/1472-6882-6-39.

23. Khurram, M.; Lawton, L.A.; Edwards, C.; Khan, F.A.; Naseemullah; Shah, Z.U.; Hameed, A. Evaluation of antibacterial potential of Quercus baloot using a rapid bioassay-guided approach. Middle East J. Sci. Res. 2013, 13, 273-279.

(C) 2015 by the authors; licensee MDPI, Basel, Switzerland. This article is an open access article distributed under the terms and conditions of the Creative Commons Attribution license (http://creativecommons.org/licenses/by/4.0/). 